UDC 368

LBC 65.271

\title{
THE CREATION OF A UNIFIED SYSTEM OF RISK INSURANCE OF HOUSEHOLDS IN RUSSIA
}

\author{
Mano A. Mgeryan \\ Volgograd State University, Volgograd, Russian Federation
}

\begin{abstract}
The growth in population's demand for insurance products - namely, the demand of Russian households, is an important factor in the development of the domestic insurance market. The analysis of peculiarities of development of modern insurance market and the depth of penetration of insurance in the financial relations of the Russians, shows, on the one hand, the need for risk insurance to households and their financial resources and opportunities for consumption of insurance products, and on the other hand, reveals a low level of insurance penetration in their economic relations. The author proposes the introduction of a system which will be the lever of cooperation of actions of the state and financial intermediaries, in particular insurance companies in order to stimulate consumption of insurance products by Russian households. A unified system will allow to increase the level of insurance literacy, which will contribute to increasing the level of trust of households to insurance companies.

Key words: insurance, risks, household, strategy of development of the insurance market.
\end{abstract}

УДК 368

ББК 65.271

\section{ФОРМИРОВАНИЕ СИСТЕМЫ СТРАХОВАНИЯ РИСКОВ ДОМАШНИХ ХОЗЯЙСТВ В РОССИИ}

\author{
Мано Агвановна Мгерян \\ Волгоградский государственный университет, г. Волгоград, Российская Федерация
}

\begin{abstract}
Аннотация. Важным фактором развития отечественного страхового рынка является рост спроса на страховые продукты со стороны населения, а именно российских домашних хозяйств. Анализ особенностей развития современного рынка страхования и глубины проникновения страхования в финансовые отношения россиян показал, с одной стороны, потребность в страховании рисков домашних хозяйств и наличие у них финансовых ресурсов и возможностей для потребления страховых продуктов, а с другой стороны, выявил невысокий уровень проникновения страхования в их экономические отношения. Автор предлагает внедрение системы, которая будет являться рычагом взаимодействия действий государства и финансовых посредников, в частности страховых организаций, с целью стимулирования потребления российскими домохозяйствами страховых продуктов. Единая система позволит повысить уровень страховой грамотности, что будет способствовать повышению уровня доверия домашних хозяйств к страховым компаниям.
\end{abstract}

Ключевые слова: страхование, риски, домашнее хозяйство, стратегия развития страхового рынка.

Современный страховой рынок тяготе-

ळे

$\dot{4}$

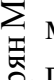

焉

гражданами, особенно в разрезе кредитно-заемного потребления. В таких условиях мы на-

() блюдаем произвольные объединения деятель- ности и продуктов страховых организаций, включая перестраховочные компании, и кредитных организаций банковского типа.

На наш взгляд, для активизации финансового поведения россиян на рынке страхования на данном этапе социально-экономического развития России, а также для того, чтобы страховой сектор стал стратегически зна- 
чимым сектором российской экономики, необходимо вмешательство государства. Такое вмешательство мы видим в создании единой национальной концепции развития отечественного рынка страхования с выделением системы или комплекса мер, стимулирующих потребление российскими домохозяйствами (именно домохозяйствами, а не отдельными индивидами) страховых продуктов для защиты их рисков (рис. 1). Такие целенаправленные меры государственного воздействия на субъекты страхового и финансового рынка будут, на наш взгляд, способствовать созданию единой системы страхования рисков домашних хозяйств в современной России.
В силу того, что население обладает существенными финансовыми ресурсами, которые могут быть вовлечены в страховой сектор экономики, нам представляется востребованным и оправданным выделение в Стратегии развития страхового рынка отдельного направления в форме Национальной системы страхования финансовых рисков домашних хозяйств. Отметим, что «Стратегия развития страховой деятельности в Российской Федерации до 2020 года» [4] предусматривает введение нового вида страхования - страхование финансовых рисков. Частично озвученный подход сочетается с нашим видением финансовых рисков домохозяйств.

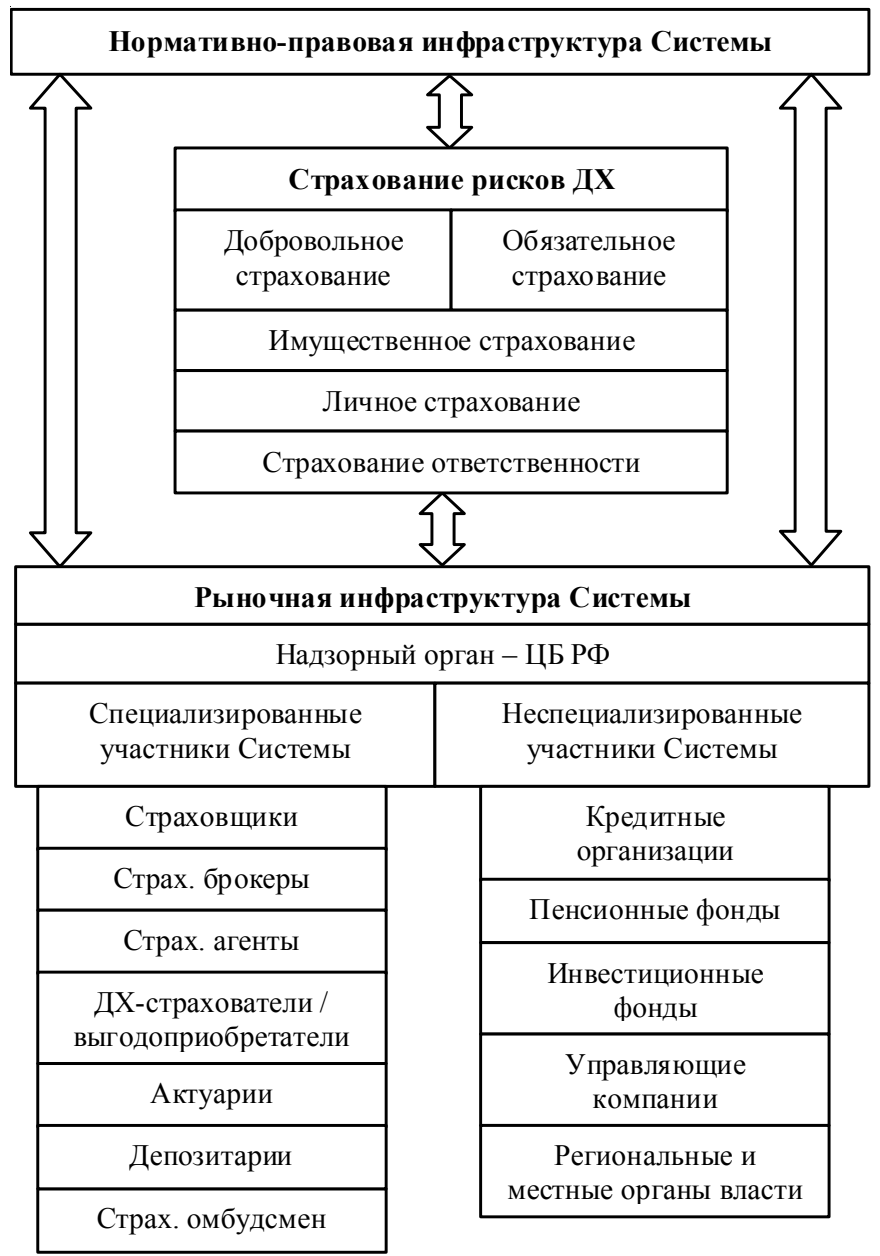

Рис. 1. Система страхования рисков домашних хозяйств

Примечания. Система является открытой (все элементы обмениваются ресурсами с внешней средой, изменяются в ответ на ее изменения и, в свою очередь, сами влияют на изменения внешней среды своими изменениями); система с обратной связью (каждый из элементов может быть рассмотрен в качестве первичного, поскольку все элементы взаимосвязаны между собой и изменения одного из них влекут изменения всех других, следовательно, первичным элементом может быть взят любой первый изменяющийся элемент, обычно первым будет изменяться государство).

Составлено автором. 
Единая система страхования рисков домашних хозяйств, по нашему убеждению, должна представлять собой совокупность взаимообусловленных и взаимосвязанных элементов (блоков):

1) нормативно-правовая инфраструктура Системы (правовые и нормативные акты, регулирующие деятельность всех участников на рынке страхования);

2) рыночная инфраструктура Системы совокупность участников Системы, включая специализированных и неспециализированных участников;

3) виды страхования финансовых рисков домохозяйств.

Функционирование данной Системы предполагает согласованные действия (меры) государства и финансовых посредников (особенно страховых организаций) в области стимулирования потребления российскими домохозяйствами страховых продуктов в целях защиты от их финансовых рисков. Особенности предложенной Системы заключаются в том, что:

- Система должна комбинировать обязательное и добровольное страхования россиян (обязательным должно быть страхование от общественно опасных рисков, все остальное - добровольным; для оптимизации Системы необходима согласованная политика в сферах обязательного и добровольного страхования). При этом обязательные виды страхования россиян традиционно рассматриваются как экстенсивный путь развития страхового рынка, а добровольные - как интенсивный путь;

- предоставление и потребление страховых продуктов должно стимулировать семейное, то есть коллективное потребление членами одного или нескольких родственных домохозяйств страховых продуктов. В настоящее время приоритет отдается стимулированию в первую очередь корпоративного потребления страховых продуктов (работодатель, страхующий своих работников получает определенные поблажки при налогообложении), затем персональному потреблению (это видно на примере действующего индивидуального подоходного налогообложении россиян). Семейное (коллективное) потребление страховых продуктов как отдельное на- правление развития страхового рынка не рассматривается;

- предоставление и потребление страховых продуктов должно ориентироваться на защиту членов домохозяйства от их финансовых рисков, комплексно защищать от рисков роста расходов и обязательств и снижения или утраты доходов, сбережений, инвестиций и активов отечественных домашних хозяйств. Это возможно только путем создания комплексных страховых продуктов совместно с другими финансовыми посредниками, чего на сегодняшний день не наблюдается;

- центром этой системы должно стать государство в лице надзорного органа - Банка России, что подразумевает внесение специальных дополнений в действующее российское законодательство:

- в Гражданский и Налоговый кодексы Российской Федерации для наделения семьи и ее членов (домохозяйства в экономическом понимании) гражданскими дееспособностью и правоспособностью, позволяющих коллективу индивидов-членов домохозяйства выступать единым хозяйствующим субъектом в финансовых отношениях (включая гражданские правоотношения и публичные правоотношения - в частности, семейное налогообложение - имущественное и подоходное);

- создание согласованной системы стандартизации «форм и методов контроля и надзора за участниками финансового рынка, в частности за субъектами страхового дела, а также введение оснований и порядка принятия органом страхового надзора решения о применении к субъекту страхового дела мер воздействия, включая меры административного наказания в виде штрафа и дисквалификации» [4];

- утверждение систематизированного перечня финансовых показателей (коэффициентов) как инструментов пруденциального надзора, позволяющих органу страхового надзора осуществлять мониторинг финансового состояния страховщиков, и качественных характеристик страховщиков, позволяющих осуществлять их сравнение и сопоставление при принятии потребителем решения о потреблении их страховых продуктов;

- национальная система страхования финансовых рисков домашних хозяйств, по 
нашему мнению, должна включать в себя и других финансовых посредников помимо страховых организаций и страховых брокеров - в их числе: коммерческие банки, депозитарии, управляющие компании, негосударственные пенсионные фонды, инвестиционные фонды. Это необходимо для создания комплексных семейно-ориентированных финансовых продуктов, включающих в себя страховой элемент. Так же должны быть возможности финансового участия в ней органов государственной власти (например, в сфере имущественного страхования жилья). Важность включения страховых компаний в пенсионную систему так же озвучена в стратегии развития, согласно которой должны быть определены формы «участия страховщиков в пенсионной системе с учетом их роли и задач, которые могут быть реализованы посредством осуществления страховой деятельности (возможность продажи страховщикам аннуитетов для выплаты пенсий, перевод гражданами части пенсионных прав страховщикам), установление условий для их деятельности, включая использование института специализированного депозитария» [4].

Формирование единой системы страхования рисков домашних хозяйств в России отвечает как общесемейным интересам членов домохозяйства, так и общественным интересам, поскольку с позиции частных интересов страховая защита домохозяйства снижает вероятность наступления негативных финансовых рисков и повышает вероятность сохранения желаемого уровня финансового благосостояния его членов.

С позиции общественных интересов снижается социальная нагрузка на государство, поскольку граждане становятся финансово активными, и исчезают стереотипы социального иждивенчества и оппортунистического поведения россиян, широко распространенные в настоящее время в российской практике. Кроме того, как отмечено в Стратегии развития, превращение страховой отрасли в стратегически значимый сектор экономики нашей страны обеспечит повышение экономической стабильности общества, «повышение социальной защищенности граждан и снижение социальной напряженности в обществе путем проведения эффективной страховой защиты имущественных интересов граждан и хозяйствующих субъектов» [4], а также обеспечит привлечение инвестиционных ресурсов в экономику страны. Ведь привлеченные страховыми компаниями средства традиционно относятся к источнику «длинных и дешевых» инвестиций в экономику страны. В отличие от банков, страховые компании не стимулируют ускорение оборачиваемости денег, поскольку не дают их потребителям в кредит, а предполагают инвестирование в долгосрочные надежные проекты с невысоким уровнем доходности.

В силу сказанного формирование Системы страхования рисков домашних хозяйств мы рассмотрим с позиции участия государства, самих страховщиков и домашних хозяйств в этом процессе (см. рис. 2).

Роль государства заключается в формировании условий активизации финансового поведения россиян и страховщиков на рынке страхования. В числе доступных для государства направлений создания условий, стимулирующих формирование страховой защиты отечественными домохозяйствами, мы выделяем следующие аспекты.

Во-первых, соответствующую государственную политику в сфере регулирования страховой деятельности. Это объясняется тем, что страховая деятельность - достаточно рисковый и социально значимый бизнес, в котором многое зависит от качества и порядочности страховой организации, следовательно, необходимо государственное лицензирование страховой деятельности вкупе с достаточно жестким государственным надзором и контролем за участниками страховых отношений по аналогии с банковской сферой. Немаловажную роль в этом процессе мы отводим созданию системы показателей, подлежащих государственному мониторингу и контролю. Эти показатели, аналогично с банковскими нормативами, будут служить базой для оценки устойчивости как страхового рынка в целом, так и отдельно взятой страховой компании. В настоящее время такие нормативы для страховых компаний отсутствуют за исключением некоторых базовых, поддерживающих систему лицензирования: минимальный размер уставного капитала, размеры страховых премий и возмещений (последние показатели просто 
М.А. Мгерян. Формирование системы страхования рисков домашних хозяйств в России

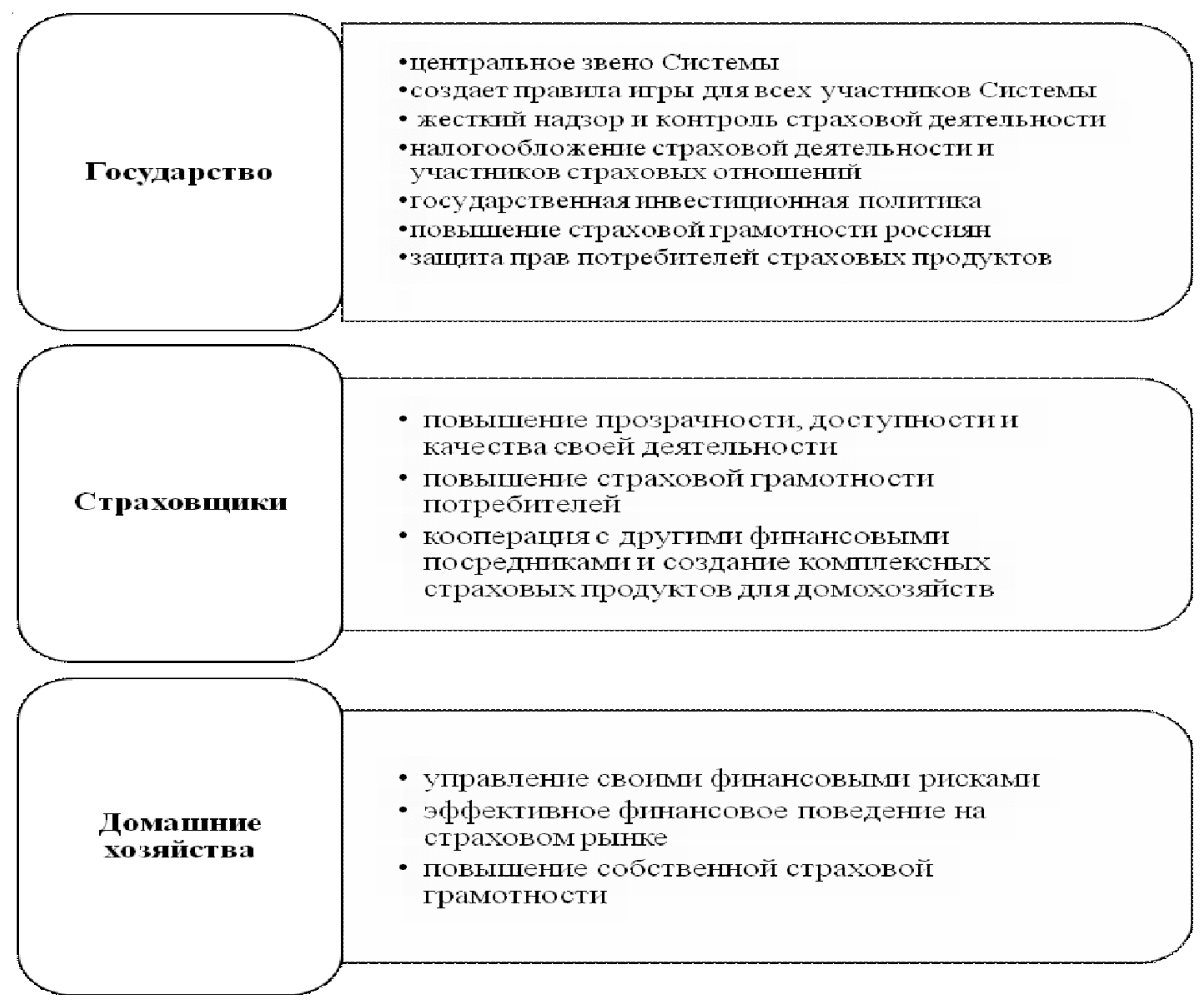

Рис. 2. Роль государства, страховщиков и домашних хозяйств в формировании Национальной системы страхования финансовых рисков домашних хозяйств

Примечание. Составлено автором.

мониторятся, не регулируются), нормативы формирования страховых резервов (для разных видов страхования установлены свои правила создания и расчета резервов). В открытом доступе системно представленные данные в выделенных аспектах отсутствуют. Оценку и анализ состояния развития страхового рынка в целом и отдельных страховщиков проводить затруднительно, особенно для потребителя с низкой финансовой и страховой грамотностью.

Во-вторых, налогообложение страховой деятельности также должно учитывать, что во всем мире для страхового бизнеса является нормой получение прибыли не за счет его основной деятельности (оказания страховых услуг), а за счет инвестиционной и финансовой деятельности - от эффективного размещения привлеченных за счет страховой деятельности средств, покрывающего издержки по основной (страховой) деятельности и приносящего доход и прибыль. Формирование благоприятного налогового климата для участников финансового рынка в Стратегии развития выделено как одна из задач развития финансового рынка к 2020 году. В рамках этой Стратегии упор делается на совершенствовании налогообложения организаций-поставщиков финансовых услуг и продуктов и физических лиц-потребителей их услуг, а также на косвенном налогообложении потребления этих услуг (налог на добавленную стоимость).

В-третьих, особое значение приобретает государственная политика в инвестиционной сфере - расширяющая или сужающая разрешенный для страховых компаний перечень и привлекательность инвестиций.

В-четвертых, государство может стимулировать финансовую активность граждан на страховом рынке посредством:

- обеспечения прозрачных и понятных для потребителя «правил игры» на страховом рынке (жесткая система государственного страхового надзора и контроля за страховым рынком и его участниками, включая стандартизацию страховых договоров и процедуры оценки ущерба), а также формирование системы открытой достоверной информации о страховом рынке и его профессиональных участниках. Схожей с нашей позиции придер- 
живается и «Банк России, нацеленный на продолжение реализации мер, направленных на повышение доступности и качества информации, лежащей в основе принятия инвестиционных решений и оценки рисков участниками финансового рынка. Поступающая информация должна соответствовать принципам своевременности, понятности, достоверности, полноты, легкости обработки и сочетаемости» [2];

- формирования дополнительных стимулов для потребления страховых продуктов населением, в частности, посредством соответствующей налоговой политики (сегодня такой механизм стимулирования «встроен» в систему отечественного подоходного налогообложения физических и юридических лиц);

- формирование как минимум удовлетворительного уровня страховой грамотности граждан (это одно из направлений повышения финансовой грамотности россиян).

От государства ожидается, что оно (согласно Стратегии развития):

- создаст условия, обеспечивающие развитие добровольных видов страхования, взаимного страхования, новых подходов к страхованию, направленных на удовлетворение массовой потребности в страховых услугах (это потребует создания соответствующего нормативно-правового поля - например, в сфере электронных продаж и потребления страхового продукта и пр.);

- повысит инвестиционную привлекательность и сформирует добросовестную конструктивную конкуренцию, обеспечивающую качество страховых услуг и эффективность страховой деятельности;

- обеспечит баланс интересов между страховщиками, страховыми посредниками и страхователями (выгодоприобретателями), выработает меры по повышению качества предоставляемых страховщиками услуг в целях защиты прав потребителей страховых услуг, а также повысит их ответственность при выборе и организации способов страховой защиты и исполнении условий договоров страхования;

- сократит предпосылки для возникновения споров между страховщиками и потребителями их услуг;
- создаст эффективные механизмы досудебного урегулирования споров, в частности - институт страхового омбудсмена;

- расширит сферы деятельности участников и субъектов страхового дела при обеспечении гарантий защиты прав потребителей их услуг;

- повысит стабильность и надежность инфраструктуры страхового рынка, оперативность и эффективность его деятельности;

- обеспечит эффективное использование бюджетных средств на страхование и повысит значимость страховой защиты (особенно в части компенсации ущерба от техногенных и природных катаклизмов).

Роль страховщиков в формировании единой системы страхования рисков домашних хозяйств в России заключается в:

- повышении качества и прозрачности страховой деятельности и доступности страховых продуктов и услуг отечественным домашним хозяйствам (в том числе за счет развития практики электронных продаж страховок);

- повышении страховой грамотности своих потребителей;

- кооперации с другими финансовыми посредниками для создания комплексных страховых и инновационных финансовых продуктов со страховым элементом.

Роль домашних хозяйств в формировании системы страхования рисков домашних хозяйств в России заключается в:

- управлении своими рисками (риски домашнего хозяйства взаимосвязаны, и если увеличиваются одни риски, вероятность наступления других тоже вырастает);

- эффективном финансовом поведении на страховом рынке (потребление страховых продуктов должно быть комплексным и вплетаться в финансовое планирование домашнего хозяйства);

- повышении собственной страховой грамотности.

\section{СПИСОК ЛИТЕРАТУРЫ}

1. Концепция развития финансового рынка России до 2020 года. Страховой сектор : совместный проект Рейтингового агентства «Эксперт РА» и Ассоциации региональных банков России. Осу- 
ществляется под эгидой Общественной Палаты РФ. - М., 2008. - $56 \mathrm{c}$.

2. О порядке осуществления Банком России мониторинга деятельности страховщиков : Указание Банка России от 18.01.2016 г. № 3935-У. - Электрон. текстовые дан. - Режим доступа: http://www. cbr.ru/finmarkets/ files/ legislation/3935-U.pdf(дата обращения: 20.09.2017). - Загл. с экрана.

3. Основные направления развития финансового рынка Российской Федерации на период 20162018 годов. - М. : Центральный банк Российской Федерации, 2016. - 76 с. - Электрон. текстовые дан. - Режим доступа: http:/www.cbr.ru/finmarkets/ files/development/onrfr_2016-18.pdf(дата обращения: 20.09.2017). -Загл. с экрана.

4. Стратегия развития финансового рынка Российской Федерации на период до 2020 года : утверждена распоряжением Правительства Российской Федерации от 29.12.2008 г. № 2043-р. - Электрон. текстовые дан. - Режим доступа: http://www. cbr.ru/sbrfr/archive/fsfr/archive_ffms/ru/press/russia 2020/strategy2020/index.html (дата обращения: 19.07.2016). - Загл. с экрана.

\section{REFERENCES}

1. Kontseptsiya razvitiya finansovogo rynka Rossii do 2020 goda. Strakhovoy sektor: sovmestnyy proekt Reytingovogo agentstva "Ekspert RA» $i$ Assotsiatsii regionalnykh bankov Rossii.
Osuschestvlyaetsya pod egidoy Obschestvennoy Palaty RF [The Conception of Development of the Russian Financial Market until 2020. Insurance Sector. A Joint Project of the Rating Agency Expert RA and Association of Regional Banks of Russia. Carried out under the Auspices of the Public Chamber of the Russian Federation]. Moscow, 2008. 56 p.

2. O poryadke osushchestvleniya Bankom Rossii monitoringa deyatelnosti strakhovshchikov: Ukazanie Banka Rossii ot 18.01.2016 g. № 3935-U [About the Procedure of Monitoring the Insurers' Activities by the Bank of Russia: the Instruction of Bank of Russia of January 18, 2016 no. 3935-U]. URL: http://www.cbr.ru/finmarkets/files/ legislation/3935U.pdf. (accessed September 20, 2017).

3. Osnovnye napravleniya razvitiya finansovogo rynka Rossiyskoy Federatsii na period 2016-2018 godov [The Main Directions of Development of the Financial Market of the Russian Federation for the Period 2016-2018]. Moscow, The Central Bank of the Russian Federation, 2016. 76 p. 4. Strategiya razvitiya finansovogo rynka Rossiyskoy Federatsii na period do 2020 goda: utverzhdena rasporyazheniem Pravitelstva Rossiyskoy Federatsii ot 29.12.2008 g. № 2043-r [The Strategy of Development of Insurance Activity in the Russian Federation until 2020: Approved by the Decree of the Government of the Russian Federation on December 29, 2008 no. 2043-r]. URL: http://www.cbr.ru/ sbrfr/archive/fsfr/archive_ffms/ru/press/russia2020/ strategy2020/index.html. (accessed July 19, 2016).

\section{Information about the Author}

Mano A. Mgeryan, Senior Lecturer, Department of Corporate Finance and Banking, Volgograd State University, Prosp. Universitetsky, 100, 400062 Volgograd, Russian Federation, MgeryanMA@volsu.ru.

\section{Информация об авторе}

Мано Агвановна Мгерян, старший преподаватель кафедры корпоративных финансов и банковской деятельности, Волгоградский государственный университет, просп. Университетский, 100, 400062 г. Волгоград, Российская Федерация, MgeryanMA@volsu.ru. 